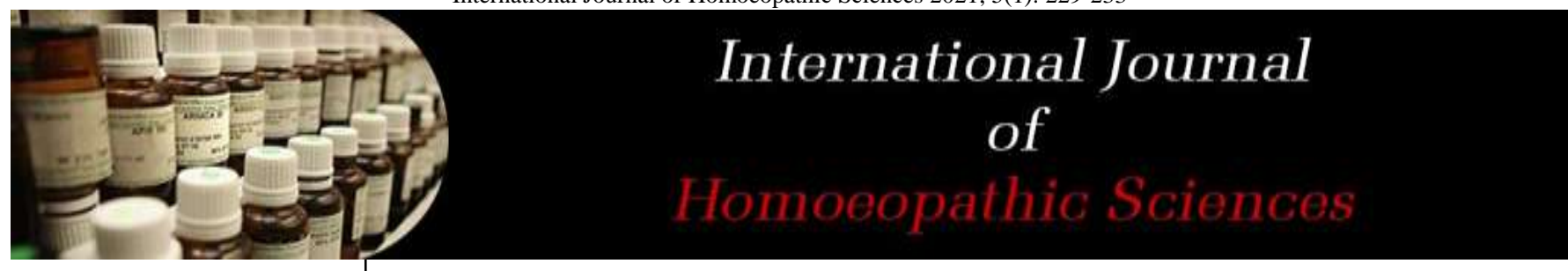

E-ISSN: $2616-4493$ P-ISSN: 2616-4485 www.homoeopathicjournal.com IJHS 2021; 5(1): 229-233 Received: 22-11-2020 Accepted: 03-01-2021

Dr. Krishneswari RS Assistant Professor, Department of Practice of Medicine, NHRIMH, Kottayam, Kerala, India
Corresponding Author: Dr. Krishneswari RS Assistant Professor, Department of Practice of Medicine, NHRIMH, Kottayam, Kerala, India

\section{Role of homoeopathic medicines in the treatment of migraine}

\section{Dr. Krishneswari RS}

DOI: https://doi.org/10.33545/26164485.2021.v5.i1d.320

\begin{abstract}
Background and Objective: Migraine is the common cause of headache. Studies shows that these patients are more prone for suicide, depression and learning problems. Though there are many modes of treatment, no method can give satisfactory result in cases of migraine. Homoeopathy has unlimited possibilities for a case of migraine as literature suggests. Through this study an attempt is made to verify the effectiveness of Homoeopathic medicines in migraine.

Methodology: Prospective, observational, non-randomized study was carried out in 30 patients within the age group of 15-45 years suffering from migraine and followed for a period of 6 months to 1 year. The outcome assessment was done by scores before and after treatment.

Results and Conclusion: Among the 30 samples, 14(46.67\%) patients showed marked improvement, $12(40 \%)$ patients showed moderate improvement and $4(13.33 \%)$ patients showed no improvement. The result shows that there is broad scope for homoeopathy in the treatment of migraine.
\end{abstract}

Keywords: Migraine, homoeopathy, international headache society

\section{Introduction}

Migraine is a type of primary headache. It is most common in high socio-economic population ${ }^{[1]}$. Migraine is a benign headache associated with other neurological symptoms ${ }^{[2]}$. Migraine includes a triad of paroxysmal headache, nausea and/or vomiting, and an 'aura' of focal neurological event (usually visual) ${ }^{[3]}$. According to Ad hoc classification Committee of the US National Institute of Health, migraine is recurrent attacks of headache with varied intensity, frequency and duration. They are commonly unilateral and are usually associated with anorexia, and sometimes with nausea and vomiting. It usually show a familial tendency [4].

According to International Classification of Headache disorders, $3^{\text {rd }}$ edition by International Headache Society, there are six major types of migraine such as Migraine without aura, migraine with aura, chronic migraine, Complications of migraine, Probable migraine and Episodic syndromes that may be associated with migraine which inturn contains so many subtypes ${ }^{[5]}$.

According to The Global Burden of Disease (GBD 2010) migraine is the first disabling in neurological diseases and ranks seventh among non-communicable diseases ${ }^{[6]}$. A systematic review conducted by Richard J Stark, K Ravishankar et al. showed that the prevalence of Chronic Migraine and Chronic Daily Headacheis less in Asia when compared to the world, but the study suggest that Chronic Migraine alone affects 23 to 65 million people in the Asia-Pacific region ${ }^{[7]}$.

Prolonged exposure to sun, sleep deprivation and travelling are found to be the most common triggering factors. Sleep and drinking hot caffeinated drinks are the most important relieving factors ${ }^{[8]}$.

The diagnosis of migraine headache is based entirely on the history. There are no radiologic studies or blood tests needed. Migraine should be suspected in those that have a family history and usually begins in teen years or early adulthood ${ }^{[13]}$.

\section{General Management}

A regulated life style is helpful, including

- Healthful diet

- Regular exercise

- Regular sleep pattern

- Avoidance of excess caffeine

- Avoidance of alcohol

- Avoidance of acute changes in stress levels ${ }^{[12]}$. 


\section{Homoeopathic role}

In Organ on of Medicine, Dr. Samuel Hahnemann emphasized Migraine as the manifestation of fundamental miasm Psora, in aphorism $80^{[14]}$. According to Richard Hughes, "Hemicrania is a disease, which requires to be closely individualized. When you have selected what seems the similimum, administer it in frequent doses, during the paroxysm, in rare ones through the interval, and give it a through trial before you change it" [15].

A systematic review conducted on four randomized controlled trials on Homoeopathic prophylaxis of headaches and migraines showed that there is no strong evidence to suggest that individualized homeopathic treatment is more effective than placebo in the prevention of migraine or headache. They also report scarcity of Randomized controlled trials and so final judgment cannot be made ${ }^{[9]}$. A prospective observational study conducted by Claudia M. Witt et al. on homoeopathic treatment reported that there is a marked and longstanding improvement in Migraine patients treated with Homoeopathic medicines [10]. A randomized, double-blind, placebo-controlled study conducted in 60 patients showed that there is significant reduction in the periodicity, frequency, and duration of migraine attacks in Homoeopathy group ${ }^{[11]}$.

It is said in modern textbooks that there is no treatment for migraine and the attack can only be prevented rather than cured. Homoeopathy has unlimited possibilities for a case of migraine as literature suggests. Many homoeopathic medicines had produced symptoms similar to that of migraine during proving and these medicines will be useful in reducing the intensity and frequency when administered according to symptom similarity. In Homoeopathy, research literature on effectiveness of migraine is less and in the available ones, the results are variable. Through this study an attempt is made to verify the efficacy of Homoeopathic medicines for this distressing illness.

\section{Materials and Methods}

Patients with migraine attending the OPD and IPD of Sarada Krishna Homoeopathic Medical College Hospital.

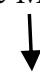

Screening done according to the inclusion and exclusion

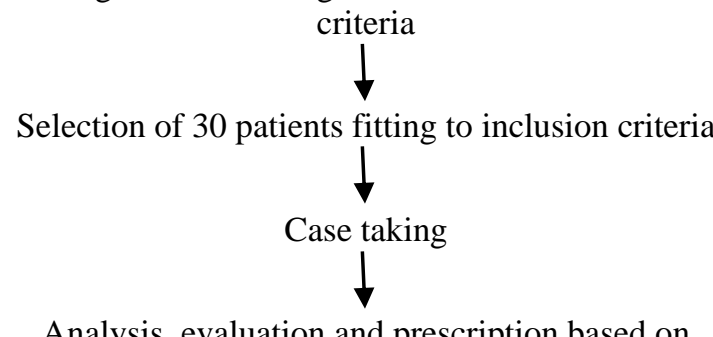

Analysis, evaluation and prescription based on Homoeopathic principles.

Review of every cases monthly for a period of 6 months to one year

Assessment of improvement using preformed disease intensity scores.

\section{Study design}

The study is prospective, observational, non-randomized study.

\section{Study population}

30 patients attending the Outpatient Department, Inpatient Department and Peripheral Health Centers of Sarada Krishna Homoeopathic Medical College in between 2011 and 2013 were taken for the study based on the inclusion and exclusion criteria.

\section{Inclusion criteria}

- Patients within the age group of 15-45years.

- Patients of both sex.

- Patients fitting to the diagnostic criteria of International Headache Society (IHS).

\section{Exclusion criteria}

- Migraine patients with complications.

- Patients with other systemic illness

- Pregnant and Lactating mothers.

\section{Study period}

The study was conducted for a period of six months to one year.

\section{Method of collection of Data}

Data were collected using the standardized case record format.

\section{Prescription}

The medicine selection is based on analysis, evaluation and prescription is based on Homoeopathic principles.

\section{Followup}

Review of the cases is done every fortnightly for a period of six months to one year.

\section{Outcome Assessment}

Improvement is assessed before and after treatment based on the preformed disease intensity scores for evaluating migraine which includes head pain, nausea, vomiting, visual symptoms, phonophobia, associated complaints, aggravation after exertion and aura symptoms

\section{Statistical analysis}

'Paired sample t test' was used to test the statistical difference before and after treatment and $\mathrm{p}$ value $<0.05$ was considered statistically significant.

\section{Results and discussions \\ Age}

30 patients were taken for the study with in the age group 15-45 years. Of this, 13 patients $(43.33 \%)$ were between 31 40 years followed by $8(26.67 \%)$ between $41-50$ years, $5(16.67 \%)$ between $11-20$ years and $4(13.33 \%)$ between 21- 30 years. This corresponds with the one-year prevalence study done on 342 patients which showed that the mean age was 32.2 years ${ }^{[8]}$.

\section{Gender}

Of the 30 cases 1 patient was male with a percentage of $3.33 \%$ and 29 patients were females with a percentage of $96.67 \%$.

\section{Occupation}

Out of thirty cases, the maximum number of cases 14 $(46.67 \%)$ were housewives; the next higher cases were 
students $5(16.67 \%)$. This was followed by cashew factory workers 4(13.33\%), tailors 3(10\%), manual laborers $2(6.67 \%)$, and accountant and teacher $1(3.33 \%)$ each. The prevalence study also revealed majority of patients were housewives ${ }^{[8]}$.

\section{Clinical features}

Representation of clinical features was depicted in Fig :1 with the symptom nausea seen in majority of patients $(60 \%)$.

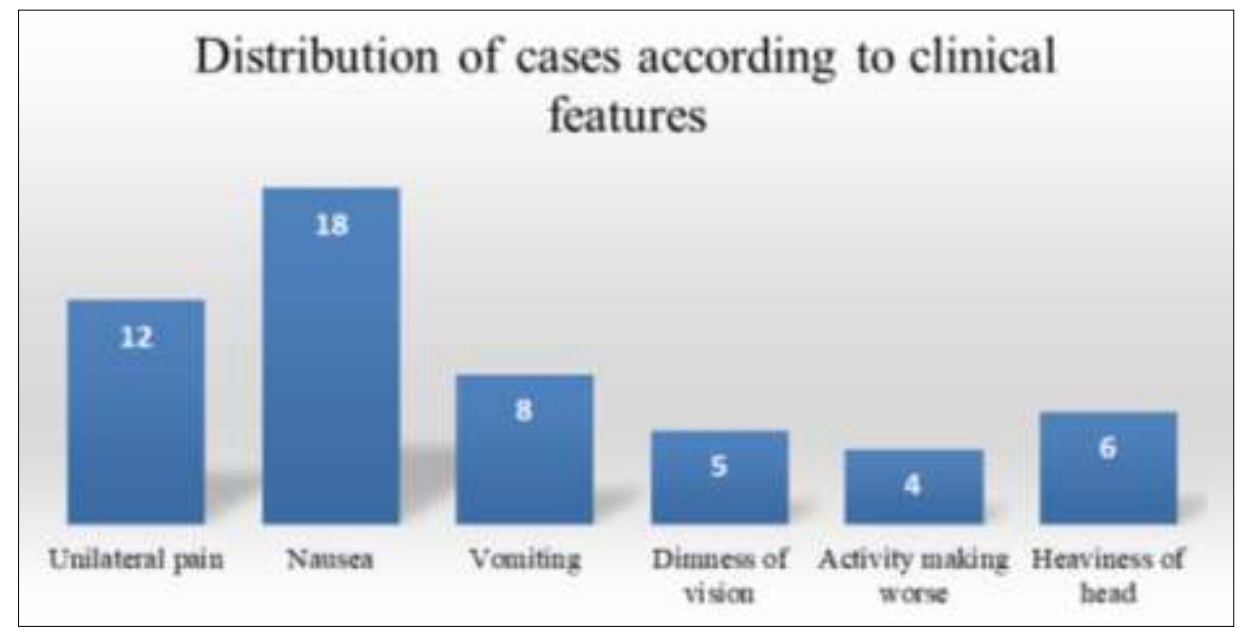

Fig 1: Clustered column showing clinical features.

\section{Comorbid conditions}

Among the 30 patients, $8(26.67 \%)$ presented with vertigo, $2(6.67 \%)$ patients presented with asthma; anxiety, allergy and functional bowel disturbances were seen in 1(3.33\%) patient each.

\section{Triggering factors}

Maximum number of patients $21(70 \%)$ had sun exposure as the triggering factor. Mental exertion stands next with 12 $(40 \%)$. Cold exposure comes next with $9(30 \%)$. Travelling and menstruation stands nextwith $7(23.3 \%)$ each. Noise stands with 6(20\%). Reading and morning time with $4(13.33 \%)$. Fanning, light and fasting comes next with
$2(6.67 \%)$ each. Prolonged sun exposure was the common triggering factor found out in the prevalence study conducted in 342 patients ${ }^{[8]}$.

\section{Clinical variants}

$24(80 \%)$ suffered from Common migraine and 6(20\%) patients suffered from Classical migraine depending up on the symptomatology.

\section{Indicated medicines}

Frequently indicated medicines in 30 cases were depicted in Fig: 2 with Natrum muriaticum covering the majority of cases.

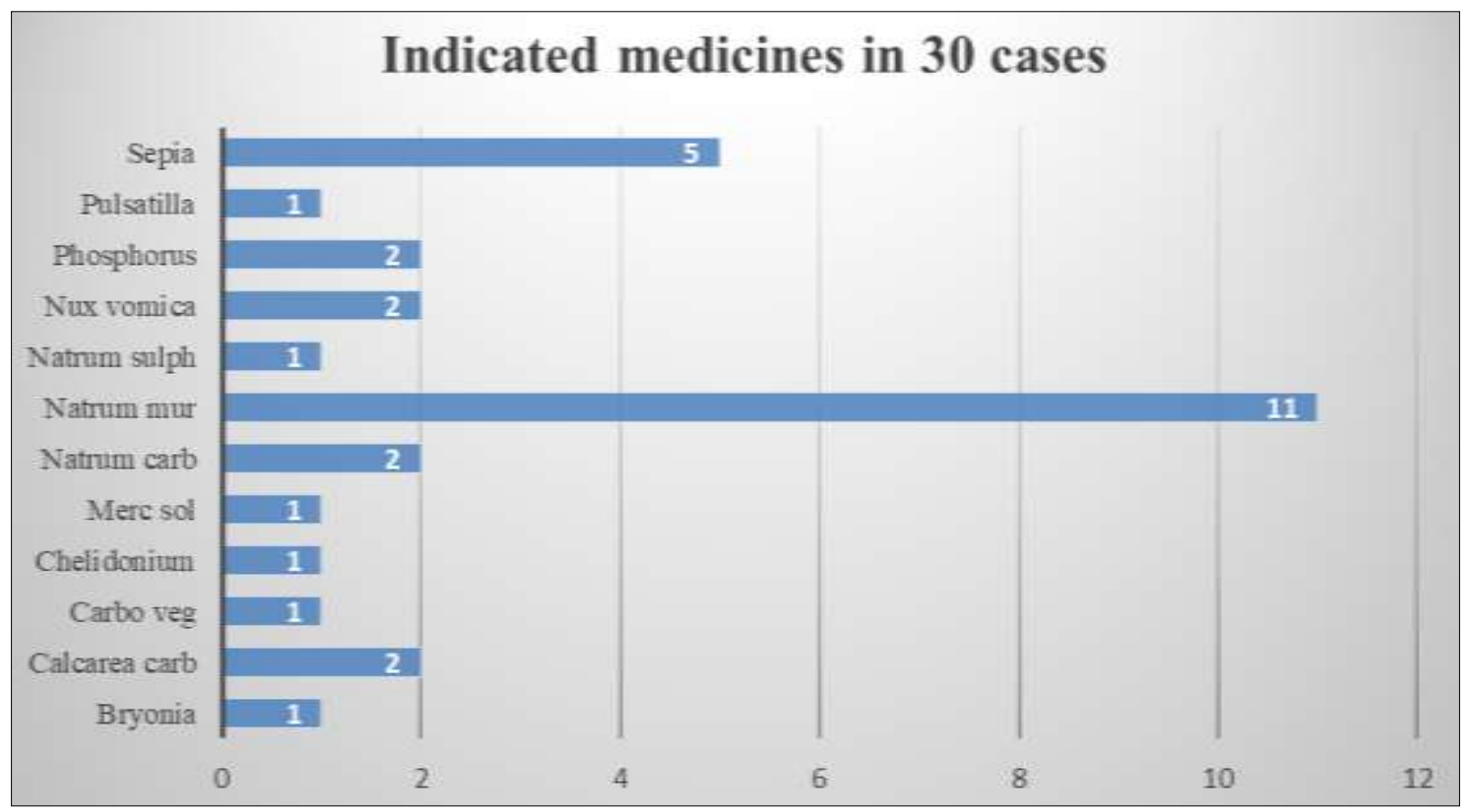

Fig 2: Bar chart showing indicated medicines

\section{Results after treatment}

Among the 30 cases enrolled, 14(46.67\%) patients showed marked improvement with Homoeopathic medicines.
12(40\%) patients showed moderate improvement and $4(13.33 \%)$ patients had no improvement. The results are depicted in Fig 3. 


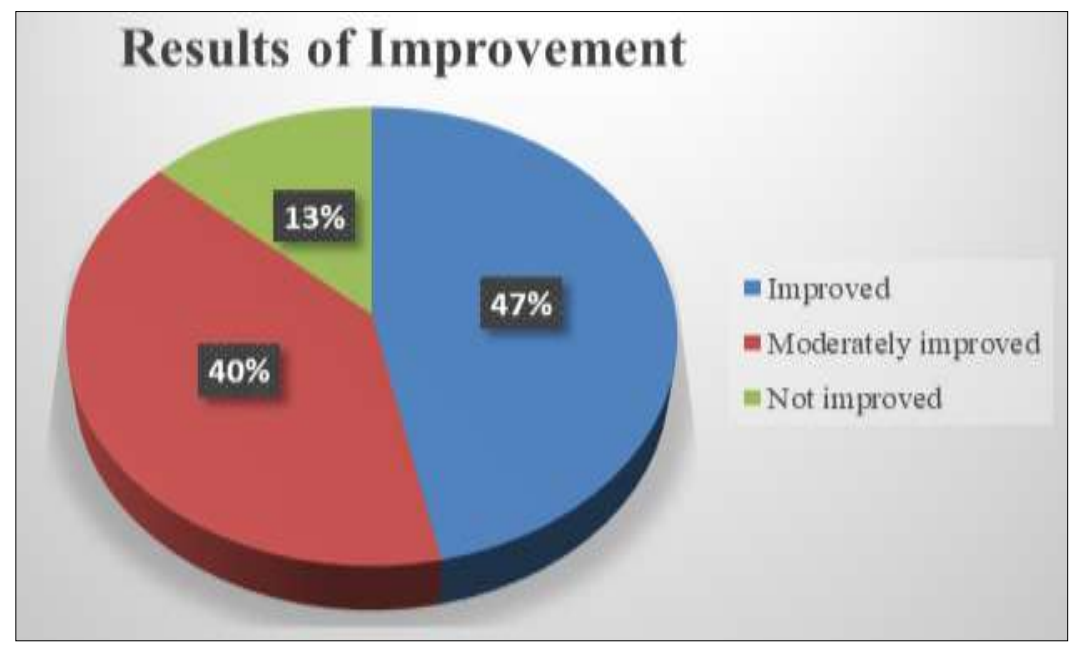

Fig 3: Pie-chart showing results of Improvement

\section{Statistical analysis of Data:}

"Paired sample $t$ test" was used to test the statistical difference before and after treatment using Disease intensity scores for evaluating migraine. The statistical analysis is depicted in Table 1.

Table 1: Statistical analysis

\begin{tabular}{|c|c|c|c|c|c|}
\hline Variable & $\begin{array}{c}\text { Before treatment } \\
\text { Mean } \pm \text { SD }\end{array}$ & $\begin{array}{c}\text { After treatment } \\
\text { Mean } \pm \text { SD }\end{array}$ & $\begin{array}{c}\text { Mean difference } \\
\pm \text { SE }\end{array}$ & t statistic & P value \\
\hline Disease intensity scores for evaluating migraine & $4.00 \pm 0.83$ & $1.23 \pm 0.97$ & $1.36 \pm 0.25$ & 11.17 & $<0.001$ \\
\hline
\end{tabular}

The statistical analysis showed that there is a significant difference before and after treatment as the $\mathrm{p}$ value is $<0.001$. Therefore, the study shows that Homoeopathic medicines are effective in reducing the symptoms of migraine.

\section{Conclusion}

This study showed the different presentations of migraine and helped to understand migraine in a detailed way. Majority of the cases showed good improvement after treatment. The result of the treatment in the study reveals that there is broad scope for homoeopathy in the treatment of migraine, as majority of the patients were relieved of their symptoms after treatment.

\section{Limitations}

Number of samples used in this study was very small. Therefore, generalisation of the results should be done cautiously. The cases were followed only for a time period of 6 months o 1 year as it was a time bound study. Bigger sample size with extended time and study with control group would provide better results.

\section{Source of funding: None}

\section{Conflict of interest: None}

\section{Acknowledgement}

I sincerely thank Dr. S.Saravanan, M.D.(Hom.), my guide for his timely support and kind advices. I also thank everyone from Sarada Krishna Homoeopathic Medical College who supported me. I extend my thanks to Dr. K.C. Muraleedhran, M.D.(Hom.), OIC, NHRIMH, Kottayam for his encouragement. I sincerely thank my patients who trusted me and without whom I could not have completed the research.

\section{References}

1. Cephalalgia-An International Journal of Headache 24. Supplement 1. www.ihs-headache.org/upload/ctclas/ihc-11.2004.

2. Sir Harrison Tinsley R. Principles of Internal Medicine. Edn 17, Mc Graw Hill medical publishing division 2008;I:95-107.

3. Clarke JH. A clinical Repertory to the dictionary of Materia Medica. Reprinted edition, B.Jain publishers (P) Ltd, New Delhi, 1998.

4. Olesen JES. The International Classification of Headache Disorders, Headache 2008;48:691-693.

5. Olesen JES, Steiner Timothy J, Bendsten Lars et al. The International Classification of Headache Disorders, International Headache Society. Edn 3.2017/18.

6. Leonardi M, Raggi A. Burden of migraine: international perspectives, Neurol Sci 2013; 34(Suppl 1):S117-S118.

7. Richard Stark J, Ravishankar K, Hua Chiang Siow, et al. Chronic migraine and chronic daily headache in the Asia-Pacific region: A systematic review. Cephalalgia. https://doi.org/10.1177/0333102412468677,10Decembe r, 2012.

8. Biman Ray K, Neelanjana Paul, Avijit Hazra et al. Prevalence, burden, and risk factors of migraine: A community-based study from Eastern India. Neurology India 2017;65(6):1280-1288.

9. Edzard Ernst. Homeopathic Prophylaxis of Headaches and Migraine? A Systematic Review. Journal of Pain and Symptom Management, Elsevier 1999;18(5):353357.

10. Claudia Witt M, Rainer Lu“dtke et al. Homeopathic Treatment of Patients with Migraine: A Prospective Observational Study with a 2-Year Follow-Up Period. The journal of alternative and complementary medicine 2010;16(4):347-355. 
11. Brigo B, Serpelloni G. Homoeopathic treatment of migraines: a randomized double-blind study of sixty cases (homoeopathic remedy versusplacebo). Berlin Journal on Research in Homeopathy 1991;1:98-106.

12. Jay VanGerpen A, Stephen Hickey, David Capobianco J. Migraine: Diagnosis, prevention and treatment; www.dcmsonline.org/jax-

medicine/2000,journals/..../migraine.html.

13. Michael Pulley $\mathrm{T}$, Nader Antonios, Walter Ray F. Migraine Headache: Origins, consequences, diagnosis and treatment; medicine/2005journals/..../migraine.

14. Dr Hahnemann Samuel. Organon of Medicine; New Delhi: B. Jain Publishers (P) Ltd; Fifth and Sixth Edition 2002.

15. Hughes Richard. The Principles and Practice of Homoeopathy; Lecture XXV, Diseases of Nervoussystem, B.Jainpublishers, New Delhi 2001, 405-440. 